\title{
Contemporary Approaches to Research on Learning Environments
}

Worldviews 
This page is intentionally left blank 


\title{
Contemporary Approaches to Research on Learning Environments Worldviews
}

\author{
edited by \\ Darrell L. Fisher \\ Science and Mathematics Education Centre \\ Curtin University of Technology, Australia
}

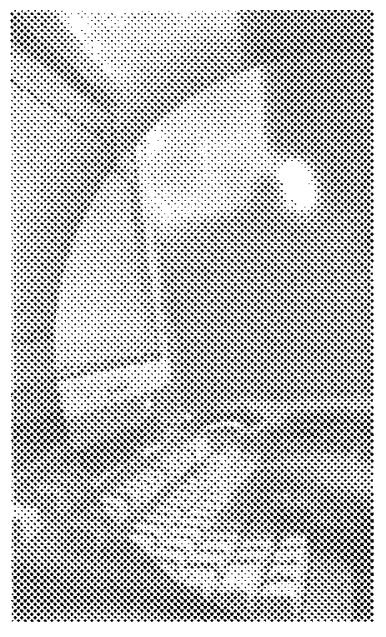

\author{
Myint Swe Khine \\ National Institute of Education \\ Nanyang Technological University, Singapore
}




\section{Published by}

World Scientific Publishing Co. Pte. Ltd.

5 Toh Tuck Link, Singapore 596224

USA office: 27 Warren Street, Suite 401-402, Hackensack, NJ 07601

UK office: 57 Shelton Street, Covent Garden, London WC2H 9HE

\section{British Library Cataloguing-in-Publication Data}

A catalogue record for this book is available from the British Library.

\section{CONTEMPORARY APPROACHES TO RESEARCH ON LEARNING ENVIRONMENTS Worldviews}

Copyright $\odot 2006$ by World Scientific Publishing Co. Pte. Ltd.

All rights reserved. This book, or parts thereof, may not be reproduced in any form or by any means, electronic or mechanical, including photocopying, recording or any information storage and retrieval system now known or to be invented, without written permission from the Publisher.

For photocopying of material in this volume, please pay a copying fee through the Copyright Clearance Center, Inc., 222 Rosewood Drive, Danvers, MA 01923, USA. In this case permission to photocopy is not required from the publisher.

ISBN $981-256-508-6$

ISBN 981-256-511-6(pbk) 


\title{
Preface
}

\author{
Theo Wubbels \\ Institute of Education \\ Utrecht University \\ The Netherlands
}

Learning environment research is booming all over the world as can be seen by the high number of books that are being published and the many recent journal articles. These articles can be found, as can be expected, in the specialised journal Learning Environments Research: An International Journal, but also, and this is remarkable, we see more and more learning environment related studies in other journals. This book with contributions on a variety of important issues is further proof of the vibrant status of the field of learning environments research. Whereas 25 years ago the field of learning environments research was dominated by scholars from Australia and the USA, nowadays studies are reported from all over the world. Europe and even now Asia are centres of excellent research as can be seen from the contributions in this book.

The tradition of learning environments research goes back to the seminal work by Rudolph Moos in the seventies of the previous century. Based on his work with families, the quality of the learning environment became accepted as a crucial factor in education. Stern, Stein and Bloom (1956) distinguished the idiosyncratic view that each person has of the environment from the shared view that members of a group hold. Following this distinction, the student's individual perception of the learning environment was acknowledged as a mediating factor between characteristics of the learning environment and a student's learning. Nowadays we see complex analyses to unravel the relationships between the shared and individual perception and the influence of these perceptions on student learning. Further, to improve student achievement, improving the learning environment became the starting point of many reform movements. Based on extensive research, a variety of economical, valid and widely-applicable questionnaires is now available for help in 
such improvements. In addition, more recent research has produced practical qualitative instruments.

Methodologically the developments over the last 25 years have been tremendous. Early studies predominantly were quantitative in nature, but now we see a broad variety of approaches, from quantitative, to qualitative, mixed methods studies and in the last five years more and more intervention studies. Early studies usually belonged to one of the following two categories: studies investigating the relations between learning environment characteristics and student outcomes and studies from the impact of interventions, for example curriculum reforms, on learning environments. Nowadays we see a broadening from these descriptive studies to intervention studies and even action research. The question addressed then is how learning environment questionnaires and other instruments can be used to bring about improvement in the quality of learning environments. Research methods have not only developed considerably in the diversity of approaches, but also in the use of advanced statistical multilevel methods.

This book convincingly shows how broad the field is and what the variety of available research methods is. Important traditional issues are covered such as relations between learning environments aspects and student outcomes. The focus of the book is however on exciting new areas such as the development of technology rich environments and advanced new research methods. Hopefully this book will encourage and guide important future research into all aspects of learning environments.

\section{Reference}

Stern, G.G., Stein, M.J., \& Bloom, B.S. (1956). Methods in personality assessment. Glencoe Ill.: Free Press. 


\section{From the Editors}

Learning environment research has undergone considerable growth in the past thirty years and has now reached a stage of notable diversity and internationalisation. Earlier studies mainly used questionnaires to assess learning environments but today both qualitative and quantitative approaches are used. Many contemporary studies are a productive combination of these two approaches. Our first book Technologyrich learning environments: $A$ future perspective has been well received by educators from all levels. This book is our second attempt at bringing together prominent educators and researchers from around the world to share their contemporary research on educational learning environments.

Our gratitude goes first to the contributors for responding to our invitation to share their work and making this book a reality. We thank our publisher, World Scientific, for taking up this project, particularly our editor, Juliet Lee who accepted this challenging task. We would very much like to thank our wives, Gail and Elizabeth, since without their encouragement and continuing support this book would not have been possible.

In the first chapter, Dorman, Fisher, and Waldrip report a study linking students' perceptions of learning environments and assessment with academic efficacy and attitude to science in Australian secondary schools. A specially validated instrument, the Students' Perceptions of Assessment Questionnaire, assessed five assessment characteristics: Congruence with Planned Learning, Authenticity, Student Consultation, Transparency and Diversity. Scales to assess attitude to science and one academic efficacy scale were employed as outcome measures. Multiple regression and structural equation modelling were used to study relationships among these variables and the extent to which a postulated model fitted the data. Results showed that classroom environment and student perceptions of assessment were significant positive predictors of academic efficacy and attitude to science.

In their chapter, Khine and Lourdusamy from Nanyang Technology University, Singapore address the issue of teachers' 
professional development in the area of interpersonal behaviour through reflective analysis of one's own behaviour and by getting feedback from students. By using the Questionnaire on Teacher-Student Interaction (QTI), the study investigated differences between the teachers' reflective analysis of their own behaviour and students' perception of the classroom interaction in Singapore schools.

The study described by Fisher, den Brok and Rickards in Chapter 3 provides information on a meta-analysis performed on a large Australian secondary student and teacher QTI data set. QTI dimension scores were examined against factors such as gender, class size and subject. To investigate separate and combined effects of variables, a hierarchical analysis of variance (distinguishing between the school, class and student level) was conducted with ML3E software. This chapter discusses the effect sizes and variance explained by these variables.

Avi Hofstein focuses on the science laboratory as a unique mode of instruction and learning environment in the fourth chapter and includes a review of the literature regarding the use of the SLEI in Australia and in Israel. Teachers' and students' perceptions of a science laboratory learning environment were measured. Research findings are presented that help us in improving the pedagogy and educational effectiveness of the laboratory.

In Chapter 5 Van Petegem and Donche write about learning environment research in higher education in Belgium. Their results show that individual differences in learning and teaching were present. Different learning patterns were also associated with different preferences for learning environments. Their studies also indicate that personal and contextual factors like learning orientations and types of education are associated with differences in learning patterns. In the final part of this chapter, an overview of possible research perspectives to elaborate their present research model is given.

From the Netherlands, den Brok, Bergen and Brekelmans discuss comparisons between students' and teachers' perceptions which are usable variables in investigating the teacher-learner process and the preparation and staff development of teachers. The study investigated divergence and convergence in perceptions for 72 teachers (from various subjects) and their classes (1,604 students) with the Questionnaire of Instructional Behaviour (QIB) and pertained to teacher control of student learning (strong, shared or loose), clarity of instruction and classroom management. Results showed that almost half of the teachers had higher perception scores than did their students, that no relationship existed 
between teacher experience and the amount of divergence, and that teaching style was related to the amount of divergence found. This suggests that more learning environment research is needed to explain convergence and divergence between student and teacher perceptions.

In Chapter 7, Kerr, Fisher, Yaxley and Fraser report two studies of student perceptions in science classrooms at the post-compulsory level. The first study used the College Science Classroom Environment Survey (CSCES) to investigate science students' perceptions of their actual and preferred psychosocial learning environments. The second study used the Technology-Rich, Outcomes-Focused, Learning Environment Inventory (TROFLEI) to assess ICT-rich psychosocial environments. Associations were examined between physical, psychosocial, and attitudinal data, and comparisons were made with results from the earlier study.

Waxman and Chang's Chapter 8 provides a very good example of the mixed method approach for examining classroom learning environments. This chapter also offers a summary of recent research that incorporates the mixed methods of survey research, such as student questionnaires, systematic classroom observation, and their application to investigate various aspects of classroom environments for educationally resilient (i.e., academically successful) and nonresilient (i.e., academically unsuccessful) students in urban elementary schools located in the USA. Importantly, the chapter addresses some of the implications of current mixed methods research for future research and teachers' professional development

Wahyudi and Treagust in Chapter 9 explore the status of science education in Indonesian lower secondary schools from a classroom learning environment perspective. They investigated how science education was delivered and how the students perceived their classroomlearning environment in both rural and urban schools. They reported that classroom observations confirmed that science teaching in urban schools was better than that in rural schools, reflecting students' perceptions of their classroom environments.

Chapter 10 by Saunders and Fisher deals with an action research approach with primary pre-service teachers to improve both university and primary school classroom environments in New Zealand. The study focused on the use of the CUCEI in a collaborative process that the lecturer and pre-service students used for examining and improving upon what was happening in their science education classes while at the same time considering their own learning environment. The study indicated 
that student teachers can be provided with strategies to examine, improve and reflect on the learning environment of their classrooms.

In Chapter 11, Koul and Fisher report the first ever large-scale study conducted in Jammu (India) where multiple research methods were used to explore the nature of classroom environments and student-teacher interactions. A sample of 1,021 students from 32 science classes in seven co-educational private schools completed the questionnaires, What is Happening in This Class (WIHIC) and the Questionnaire on Teacher Interaction (QTI), as well as an attitude scale. The quantitative data provided a starting point from which other qualitative methods (interviews and observations) were used to gain a more in-depth understanding of the classroom environment. It is hoped that the information in this chapter will give readers an understanding of the existing learning environments in Jammu, India.

Wanpen and Fisher in Chapter 12 describe a case study conducted in a tertiary computer classroom in the northeast region of Thailand. The Constructivist Learning Environment Survey (CLES) was used with a large sample of students to determine its reliability for use in Thailand, and then administered to a class of students taking a computer course to find out their actual and preferred perceptions of their learning environments. These data were then used in a practical way to improve the class environment.

Templeton, Johnson, Lee and Guofang from the USA describe how they have investigated the factors that professional staff, faculty, and administrators in the College of Education and Human Services (COEHS) at Lake State University (LSU) described as conducive to an improved college (working, teaching and learning) environment. Participants completed the School-Level Environment Questionnaire. Their findings and a description of their interesting process are reported in Chapter 13.

In New Zealand, Falloon (Chapter 14) documents key findings of an eighteen-month case study into a learning environment involving Year 5 and Year 6 students at a suburban primary school. It examines the nature of teacher and student work practices in an environment where there was a ratio of one computer to approximately two students, and details the complexity of the interrelationship between teacher philosophy, curriculum design, and classroom organisational systems, that significantly impacted upon student work and social performance. It presents and discusses data captured using Camtasia video recording software, which enabled unique and unscripted "insider views" to be 
gained of the manner in which students worked with the teacher, each other, and the software, as they undertook their learning tasks.

Kyriakides from the University of Cyprus presents the results from a study attempting to show that teacher effectiveness research and research into teacher interpersonal behaviour can help us explain most of the student variance at classroom level. In this chapter the main findings of both teacher effectiveness research and research into teacher interpersonal behaviour are presented. A stratified sample of 32 primary schools in Cyprus was selected and two questionnaires measuring student perceptions of teacher behaviour in the classroom according to each research tradition were administered to all Year 6 students from each class of the school sample. It was found that the data collected from most of the scales of both questionnaires were associated with student achievement gains in both cognitive (Mathematics and Greek Language) and affective outcomes of schooling.

In Chapter 16, Hirata, Ishikawa and Fisher report on three studies describing associations between students' perceptions of their classroom environment and their individual characteristics in Japanese higher education. The first study involved the use of the CUCEI: College and University Classroom Environment Inventory and the Locus of Control Scale which were administered to 406 students. The analysis of data revealed that students' academic achievement and internal locus of control were associated with satisfaction from learning. The secondary study concerned the analysis of data from 100 students and clarified the relevance that existed between students' perceptions of actual and preferred satisfaction as well as innovation in learning. In the third study analysis of covariance structures, using structural equation modelling was involved. The results suggest that student perceptions of their classes are clearly relevant to individual student characteristics and needs.

Dorman, Aldridge and Fraser present their finding in the use of structural equation modelling to investigate associations between classroom environment and outcomes in Australian secondary schools. The 80-item Technology-Rich Outcomes-Focused Learning Environment Inventory (TROFLEI) was used to assess 10 classroom environment dimensions. A sample of 2,178 high school students from Western Australia and Tasmania responded to the TROFLEI and three student outcome measures: attitude to the subject, attitude to computer use and academic efficacy. Confirmatory factor analysis using LISREL supported the 10 scale a priori structure of the instrument. Multiple regression identified particular classroom environment scales that were 
significant predictors of three outcome scales. Structural equation modelling using LISREL revealed that teacher support and equity predicted attitude to subject and that differentiation, task orientation, computer usage and young adult ethos predicted attitude to computer use. Overall, the modelling indicated that improving classroom environment has the potential to improve student outcomes.

Lipponen, Lallimo and Lakkala from the University of Helsinki, Finland present their ideas on designing infrastructures for learning with technology in Chapter 18. They argue that the functionality, the implementation and use of technology in schools and in workplaces is based on, and requires the creation of, a set of interconnected structural elements. It is further explained that these interconnected structural elements, such as social practices, and educational use of technology form infrastructures that can be designed in a similar way as, for instance, technical infrastructures are designed. They call these infrastructures learning-oriented infrastructures. Learning-oriented infrastructures provide a framework for designing the entire structure of teaching and learning with technology. In this chapter, they analyse the characteristics of these infrastructures in complex learning environments by demonstrating how they are related, and support working with technology.

Chapter 19 deals with assessing the effectiveness of a blended webbased learning environment in an Australian high school. Chandra and Fisher present the findings of a study in which Getsmart, a teacher designed website, was blended into science and physics lessons at an Australian High School. It shows how the results of learning environments research were used in assessing the effectiveness of the approach from the students' perspective. The investigation also gave an indication of how effective Getsmart was as a teaching model in such environments.

From Taiwan, Huang describes in Chapter 20 the validation of the College and University Environment Inventory. The results of an application of the inventory revealed that, in Taiwan, most juniors had favourable relations with other students and with administrative staff, and perceived positively their library resources and emotional development. Student-faculty relations, university system support to student affairs, and language learning, however, may need to be improved. The implications of these findings are discussed in this chapter.

In Chapter 21, Wahyudi and Fisher describe the working environments in an Indonesian junior secondary school context. Using 
the Indonesian version of the School Level Environment Questionnaire (SLEQ), the study found that teachers view their school environments positively on all scales, except that of Staff Freedom. A comparison between actual and preferred perceptions showed statistically significant differences on all scales, except Staff Freedom and Work Pressure. It was also found that urban school teachers viewed their school environment less favourably than did their counterparts in rural and suburban schools. Statistically significant differences were found on the Participatory Decision Making and Work Pressure scales. This study suggests that these findings should be used as a starting point for improving working environments in rural, suburban, and urban schools in Indonesia.

Telli, Cakiroglu and den Brok investigated Turkish secondary students' perceptions of their classroom learning environment and attitude toward biology. The data were gathered from 1,983 ninth and tenth grade students from 57 biology classes at schools in two major Turkish cities. Data were collected with an adapted and translated version of the What is Happening in This Classroom (WIHIC) instrument and the Test of Science Related Attitudes (TOSRA). Correlation and regression analyses revealed that students' perceptions of their learning environment in biology were significantly associated with their attitudes. In addition, results of the study revealed that there were significant differences in gender and grade level. The authors discuss these findings in Chapter 22 and compare them with prior learning environment studies.

Quinton provides a critique on the possible future of learning in Chapter 23. He describes how the potential of the Internet and the technologies it inspires makes it feasible to not only access and manage information in productive and efficient ways, but also to create an environment in which we can deliver dynamically interactive, personalised solutions tailored to the needs and preferences of all learners. He presents the challenge to us of harnessing technological innovations in ways that will assist us to create learning environments in which we can deliver high quality learning outcomes relevant to the changing needs of learners.

In Chapter 24, Chai and Tan explain that Computer-Supported Collaborative Learning (CSCL) is an emerging field of research that has gained significant momentum in the past decade. For its relatively short history, it has been associated with three perspectives of learning: acquisition, participation, and knowledge creation. Their chapter 
focuses on CSCL for knowledge creation, particularly the Knowledge Building approach proposed by Bereiter and Scardamalia. It includes the theoretical foundation of Knowledge Building, its relevance in the Knowledge Age, some key research directions and methodologies, and discussion on some key challenges.

Chard in Chapter 25 describes how in recent times learning environment research has moved into distance and web-based learning environments, with new instruments being developed for the purpose of evaluating and improving these environments. This chapter discusses the development of learning environment instruments from their roots in psychosocial research to the current development of learning environment instruments for the evaluation of virtual learning environments including 3D virtual worlds designed for learning.

It has been a long process and a formidable task to compile the twenty five chapters for this book. But we are very pleased to see the final result from which we hope will establish a landmark in the history of learning environment research.

Darrell L. Fisher

Curtin University of Technology Australia

Myint Swe Khine Nanyang Technological University Singapore 


\section{About the Contributors}

Jill M. Aldridge is a Senior Lecturer at the Science Mathematics Education Centre at Curtin University of Technology, Perth, Australia. Her research is in the field of teaching and learning. Currently, her focus is on the integration of ICT into classrooms and whether this leads to more individualised and outcomes-focused learning environments.

Rosalyn Anstine-Templeton is Dean of the College of Education and Human Services at Marshall University in Huntington, West Virginia. Her research interests include studying learning environments in the field of at risk populations and higher education.

Theo Bergen is Professor of Educational Sciences, holding a chair in teacher performance at the Graduate School of Teacher Education of the Radboud University Nijmegen (The Netherlands). A central issue in his research interest is the learning of teachers in the context of innovation. Currently, his research focuses on how teachers' professional development can be stimulated by means of collegial coaching.

Mieke Brekelmans is Associate Professor in a teacher training and educational research group of the Institute of Education (IVLOS) at Utrecht University (The Netherlands). Her research is in the field of teaching and teacher education. Currently, her focus is on the relation between teacher thinking and action, and the development of teaching during the professional teacher career.

Perry den Brok is Associate Professor in a teacher training and educational research group of the Institute of Education (IVLOS) at Utrecht University (The Netherlands). His research is in the field of teaching and teacher education. Currently his focus is on multicultural and intercultural studies on classroom environments, and factors that explain differences in student perceptions of teaching.

Jale Cakiroglu is Assistant Professor at the Department of Elementary Education, Middle East Technical University, Ankara, Turkey. Her 
research interests include teacher efficacy beliefs, learning environments research and the nature of science.

Ching Sing Chai is a Lecturer in the Learning Sciences and Technologies Academic Group, National Institute of Education, Nanyang Technological University, Singapore. His areas of research interests are computer supported collaborative learning and using information technologies as cognitive tools.

Vinesh Chandra is a Senior Mathematics and Science Teacher at Mansfield State High School in Queensland, Australia. He graduated with his doctorate in science education from Curtin University of Technology in 2005. His research interests include classroom and online pedagogies, gender issues and applications of technology in science education. For his innovative approaches to teaching, he was awarded the prestigious Queensland Premiers Smart State Teacher Excellence Scholarship in 2002. In 2005, he received the Queensland Society of Information Technology in Education (QSITE) Teacher of the Year award.

Hui-Li Chang earned her doctorate degree in Mathematics Education at The University of Houston, USA. She was a Post-Doctoral Research Fellow at the USA Department of Education, Center for Research on Education, Diversity and Excellence (CREDE) where she directed the "Effective Teaching and Learning for Language Minority Students in Mathematics" project. She was also a principal researcher on the "Preservice Teacher Education for Diversity Research Synthesis Project". Dr. Chang is currently teaching graduate research courses at NationalLouis University in Illinois.

Susan M. Chard is a Senior Lecturer at Whitireia Community Polytechnic, Porirua New Zealand. Her research is in the field of web based learning. Currently, her focus is the development of web based 3D learning environments and the methods of evaluating these environments.

Vincent Donche is a Researcher of the Institute of Education and Information Sciences at the University of Antwerp, Belgium and works in the research group EduBROn [Counselling, Research \& Development in Education] [www.edubron.be]. His research interests include learning 
styles, teaching styles, autonomous learning and constructivist learning environments. He is completing his doctoral degree focusing on student and teacher learning in higher education.

Jeffrey P. Dorman is a Reader in the School of Education at the Brisbane campus of the Australian Catholic University. His research interests include the study of learning environments and the use of structural equation modelling to analyse educational research data.

Garry Falloon is a Senior Lecturer at the Faculty of Education at the University of Auckland, but is presently seconded to the New Zealand Ministry of Education to develop and manage the Digital Opportunities Projects (www.digiops.org.nz). He recently completed doctoral research on student learning in a digital classroom environment, and has research interests in examining the efficacy of such organisational systems for supporting student learning, and in determining if, how, and where computers can best support overall student development.

Darrell L. Fisher is Professor of Science Education and Deputy Director of the Science and Mathematics Education Centre at Curtin University of Technology, Australia. His major research interests include classroom and school environments, and curriculum issues related to science, particularly curriculum evaluation. He has published and presented on these topics throughout the world. He is a Fellow of the Australian College of Education and the Regional Editor for Asia and Australia of Learning Environments Research: An International Journal. He is a world leader in learning environment research and co-author of the book published by World Scientific, Technology-rich Learning Environments: A Future Perspective.

Barry J. Fraser is Professor and Director of the Science and Mathematics Education Centre at Curtin University of Technology, Australia. He is co-editor of the 72-chapter International Handbook of Science Education published by Kluwer, and Editor-in-Chief of the Kluwer journal Learning Environments Research: An International Journal. He is a fellow of the American Association for the Advancement of Science, International Academy of Education, Academy of Social Science in Australia and Australian College of Education. He is the 2003 recipient of the Outstanding Contributions to Science Education through Research Award from the National Association for Research in 
Science Teaching in the USA. He is an eminent scholar in learning environment research.

Sonomi Hirata is presently in the Faculty of Human Development at Hakuoh University in Japan. Prior to that, she held a position at the Department of Human Science at Waseda University in Tokyo. She received her BSc and MSc in Human Science, and a PhD from Waseda University. She has taught courses in teacher-training; educational psychology and in general subjects in psychology. Her work has been published in journals such as Learning Environments, an International journal, the Japanese Journal of Counseling Psychology, and the Japanese Journal of Criminal Psychology as well as in proceedings of several international conferences. Her research interests include examining the relation between classroom climate and student behaviour, and constructing psychological measurements for learning environment design.

Avi Hofstein holds a $\mathrm{PhD}$ in science education (chemistry) from the Weizmann Institute of Science in Israel. He is a Professor and Head of both the Chemistry Group and the Science for All programs in the Science Teaching Department at the Weizmann Institute of Science, Israel. He has been involved in all facets of the curricular process in chemistry namely development, implementation, and evaluation. He has conducted research in many areas of science education (e.g. learning environment, learning difficulties in science learning, professional development and laboratory work). In recent years, he has been involved in the development of leadership amongst chemistry teachers in Israel in order to promote reform in the way chemistry is taught in high schools in Israel.

Shwu-yong L. Huang is an Associate Professor at the Center for Teacher Education, National Taiwan University, and was formerly the Director of the Center at National Tsing Hua University. Prior to her return to Taiwan in 1999, she taught at the University of Houston, USA, and served as the principal of a Chinese school and as President of the Chinese American Educational Research and Development Association in the USA. Her research interests focus on school and classroom learning environments and on teacher education. She has received research awards in Taiwan and abroad. Currently, as a co-principal 
investigator, she is helping to establish a large-scale Taiwan Higher Education Data System.

Makoto Ishikawa works at the Center for Educational Research and Development, Joetsu University of Education in Japan. He received his $\mathrm{PhD}$ from Waseda University. He has taught courses in teacher-training; ICT for education, ICT for Teachers, and in other subjects in ICT. His research interests include evaluating computer-supported cooperative work and e-learning environments.

Celia E. Johnson is Associate Professor at Bradley University in Peoria, Illinois. Her research interests include studying learning environments in the field of at risk populations, special education and early childhood education.

Craig R. Kerr is a Science and Mathematics Teacher at The Don College in Devonport, Tasmania and a $\mathrm{PhD}$ graduate of Curtin University of Technology Australia. His research interests include the study of science learning environments, and particularly, the design and integration of ICT-rich learning areas. Currently, his focus is on the holistic study of psychosocial and physical aspects of ICT-rich learning environments, and associations between these factors and student satisfaction with learning.

Myint Swe Khine is Associate Professor and Coordinator of Master Degree Program at the National Institute of Education, Nanyang Technological University, Singapore. He received his Master degrees from the University of Southern California, USA and University of Surrey, UK; and Doctor of Education from Curtin University of Technology, Australia. He has co-authored and published books which include Studies in Educational Learning Environments: An International Perspective (World Scientific), Engaged Learning with Emerging Technologies (Springer), and Technology-rich Learning Environments: A Future Perspective (World Scientific).

Rekha B. Koul has taught high school students for a short time, followed by teaching at undergraduate level and has finally conducted over twelve years of research/extension activities aimed at women as main beneficiaries at the Agricultural University Kashmir, India. She obtained her Doctor of Science Education from Curtin University of 
Technology, Australia. At present she is working on learning environment projects in Australia. Her most recent research has involved studies of classroom learning environments and teachers' interpersonal behaviour.

Leonidas Kyriakides is Assistant Professor in Educational Research and Evaluation at the University of Cyprus. His field of research and scholarship concerns the evaluation of educational effectiveness whether of teachers, schools or educational systems. Specifically his research interests are on the development of generic and differentiated model of educational effectiveness, the evaluation of pupil progress and the application of effectiveness research to the improvement of educational practice. He is the author of more than 35 research papers in international journals, five books and 18 chapters in books. His most recent book (with Campbell, Muijs and Robinson) is Assessing Teacher Effectiveness: Towards a Differentiated Mode, published by RoutledgeFalmer in 2004.

Jiri Lallimo is a Researcher at the Centre for Research on Networked Learning and Knowledge Building in the Department of Psychology of the University of Helsinki, Finland. His main area of research at the present concerns how psychological and sociocognitive viewpoints of organisational intelligence are embedded in knowledge sharing, and collective efforts for building and advancing knowledge.

Minna Lakkala has a background in general psychology and computer science. She has an extensive experience of teachers' training in the educational use of ICT. Her main research interest at present is teachers' pedagogical expertise in relation to collaborative inquiry learning. Lakkala has participated in large national and international research projects concerning the use of ICT at schools. She has participated in the development of educational ICT, and ICT-related user training as a consultant and educator from the beginning of the 1980s. Currently she is pursuing her doctoral studies at the Centre for Research on Networked Learning and Knowledge Building in the Department of Psychology at the University of Helsinki, Finland.

Hwa Lee is Assistant Professor at Bradley University in Peoria, Illinois. Her research interests include studying learning environments in the area of special education and early childhood education. 
Lasse Lipponen is a Senior Lecturer in educational psychology at the University of Helsinki, Finland at the Department of Applied Educational Science. His main research area is collaborative and technology mediated practices of learning and working. Lipponen has considerable expertise in design, development, experimentation, and analysis of new technology-supported learning environments. During the past years he has been involved in several EU and nationally funded projects. Lipponen has taught at several Finnish universities and given numerous expert lectures on new technology and its use in education and working life. He has authored a number of articles on technology supported learning, and functioned as a referee in several conferences and journals.

Atputhasamy Lourdusamy is a Senior Fellow in the Learning Sciences and Technologies Academic Group, National Institute of Education, Nanyang Technological University, Singapore. His areas of research interests are teaching, learning and teacher education.

Peter Van Petegem is Professor and President of the Institute of Education and Information Sciences at the University of Antwerp, Belgium. He is the leader of the research group EduBROn (www.edubron.be). His major research interests include quality concern and school effectiveness, autonomous learning, learning styles and educational policies. Recently he also focuses on learning environment research that tries to integrate the above-mentioned topics.

Stephen Quinton is employed by the Division of Humanities at Curtin University, Australia as an Academic Researcher in the design and delivery of multi-modal learning environments. He is actively involved in several research projects that focus on the effective application of convergent technologies to educational practice. His current research activities include the development of a database managed learning objects framework as applied to the design of online learning environments and the adaptation of learning styles and multiple intelligences theory to the provision of customised learning solutions. The practical outcome will be to demonstrate how individualised learning strategies can be delivered in an online teaching environment.

Tony Rickards is a Senior Lecturer in science, mathematics and technology education at the Science and Mathematics Education Centre, 
Curtin University of Technology, Australia. He has held posts at the University of Western Australia, in the Graduate School of Education, and the University of Southern Queensland, where he was founding Director of ITEL, an Information Technology Enhanced Learning research centre. He has over 20 years of teaching experience in computer education at all levels of education in Australia. His current research, publications and professional involvement center on teacher-student interpersonal behaviour in science, mathematics and technology-rich learning environments.

Kathryn J. Saunders is a Senior Lecturer in the Mathematics, Science and Technology Education Department, School of Education, University of Waikato, New Zealand and is currently completing her doctoral degree at Curtin University of Technology, Australia. Her research interests include the study of learning environments with a current focus in the area of pre-service education.

Seng Chee Tan is currently the Deputy Head of the Learning Sciences and Technologies academic group in the National Institute of Education, Singapore. He holds a concurrent appointment as an Assistant Director in the Educational Technology Division, Ministry of Education. One of his key roles is to bridge the research communities on educational technology between the two organisations. His research interests include using computers as cognitive tools and Computer-Supported Collaborative Learning, particularly in the area of knowledge creation.

Sibel Telli is a $\mathrm{PhD}$ Student in Secondary Science and Mathematics Education at the Middle East Technical University in Turkey. She has been a high school biology teacher for 11 years. Her PhD project focuses on learning environments research, in particular teacher-student interpersonal behaviour.

David F. Treagust a Professor of Science Education in the Science and Mathematics Education Centre at Curtin University of Technology, Australia. His primary research interests are related to understanding students' ideas about science concepts, and how these ideas contribute to conceptual change and can be used to enhance the design of curricula and the classroom learning environment. He is the author or co-author of over 120 science education articles in refereed journals and has presented over 200 papers at international, and at Australian national and state 
conferences. He has frequently consulted on projects in developing countries and has supervised many doctoral students from developing and transitional societies in Asia and Africa.

Guofang Wan is Associate Professor at Ohio University in Athens, Ohio, USA. Her research interests include studying learning environments in the field of language arts and English as a second language education.

Wahyudi is a Science Teacher of SMA Negeri 1 Banjarmasin - a state senior secondary school, Kalimantan Selatan, Indonesia. After completing his doctoral degree in the Science and Mathematics Education Centre, Curtin University of Technology, Australia, he is now pursuing his university teaching as Lecturer at the Faculty of Education and Pedagogy, Ahmad Dahlan University, Yogyakarta, Indonesia.

Supatra Wanpen is a Language and Computer Lecturer at Udon Thani Rajabhat University, Thailand. She has just completed a Doctor of Science Education degree at Curtin University of Technology in Australia. Her research interests include learning environments and technology in education. Her focus now is on improving learning environments in computer classes.

Bruce G. Waldrip is Associate Professor of Science Education at the University of Southern Queensland, Toowoomba, Australia. His research agenda has been varied yet focused on student learning. Past and present research include an investigation into students' reactions to assessment strategies; factors that effect students' perceptions of their classroom environment; implementation of a school and teacher change research project for both primary and secondary science teachers; students' worldviews; a study of cultural factors affecting students' learning; and Student understanding of concepts. He currently lectures on science education and research methodology.

Hersh C. Waxman is Professor of Educational Leadership and Cultural Studies in the College of Education at the University of Houston, USA; a Principal Researcher in the National Center for Research on Education, Diversity, and Excellence; and a Principal Investigator in the MidAtlantic Regional Educational Laboratory for Student Success. His research focuses on equity, excellence, and social justice issues, such as 
closing the achievement gap and improving the education of students at risk of failure. He has published articles on these topics in journals such as Journal of Educational Research, Learning Environments Research: An International Journal, Journal of Education for Students Placed at Risk, and Urban Education. Some of the books he has recently co-edited include: Observational Research in USA classrooms: New Approaches for Understanding Cultural and Linguistic Diversity (Cambridge, 2004); Educational Resiliency: Student, Teacher, and School Perspectives (Information Age, 2004); and New Directions for Teaching Practice and Research (McCutchan, 1999).

Bevis G. Yaxley is currently Director of the Institute for Inclusive Learning Communities, at the University of Tasmania, Australia. He has been an Adjunct Associate Professor, at the Key Centre for Science \& Mathematics Education in Curtin University of Technology and Principal Science Education Officer, Department of Education, Tasmania. He was given the Outstanding Educator Award of the Tasmanian Chapter, Australian College of Educators (2004). He has conducted research and published papers in curriculum development, educational leadership, teaching and the role of ICT in education and has had extensive experience in supervising students undertaking higher research degrees. He specialises in philosophic inquiry in education, with a particular emphasis on narrative studies. 


\section{Contents}

$\begin{array}{lr}\text { Preface } & \mathrm{v} \\ \text { From the Editors } & \mathrm{vii} \\ \text { About the Contributors } & \mathrm{xv} \\ \text { Chapter 1 } & \\ \text { Classroom environment, students' perceptions of } & \\ \text { assessment, academic efficacy and attitude to science: } & 1 \\ \text { A LISREL analysis } & \end{array}$

Jeffrey P. Dorman, Darrell L. Fisher and Bruce G. Waldrip

Chapter 2

Reflective analysis of teachers' behaviour and

students' perception of classroom interaction

Myint Swe Khine and A. Lourdusamy

\section{Chapter 3}

Factors influencing students' perceptions of their

Teachers' interpersonal behaviour: A multilevel analysis

Darrell L. Fisher, Perry den Brok and Tony Rickards

\section{Chapter 4}

Improving the classroom laboratory learning

environment by using teachers' and students' perceptions

Avi Hofstein

\section{Chapter 5}

Learning environment research in higher education:

Assessing patterns of learning and teaching

Peter Van Petegem and Vincent Donche 


\section{Chapter 6}

Convergence and divergence between students' and teachers' perceptions of instructional behaviour in Dutch secondary education

Perry den Brok, Theo Bergen and Mieke Brekelmans

\section{Chapter 7}

Studies of students' perceptions in science classrooms at the post-compulsory level

Craig R. Kerr, Darrell L. Fisher, Bevis G. Yaxley and Barry J. Fraser

\section{Chapter 8}

Mixed method approaches for examining classroom learning environments for resilient and nonresilient students in urban elementary schools

Hersh C. Waxman and Hui-Li Chang

\section{Chapter 9}

Science education in Indonesia:

A classroom learning environment perspective

Wahyudi and David F. Treagust

\section{Chapter 10}

An action research approach with primary pre-service teachers to improve university and primary school classroom environments

Kathryn J. Saunders and Darrell L. Fisher

\section{Chapter 11}

A contemporary study of learning environments in Jammu, India

Rekha B. Koul and Darrell L. Fisher

\section{Chapter 12}

Creating a collaborative learning environment in a computer classroom in Thailand using the CLES

Supatra Wanpen and Darrell L. Fisher 


\section{Chapter 13}

Becoming more efficient: One college's use of the SLEQ

Anstine-Templeton, R., Celia E. Johnson, Hwa Lee and

Guofang Wan

\section{Chapter 14}

"Learning digitally" - E-classrooms: Computers looking for a problem to solve?

Garry Falloon

\section{Chapter 15}

Measuring the learning environment of the classroom and its

effect on cognitive and affective outcomes of schooling

Leonidas Kyriakides

\section{Chapter 16}

The use of the CUCEI for monitoring students' characteristics in Japanese higher education

Sonomi Hirata, Makoto Ishikawa and Darrell L. Fisher

\section{Chapter 17}

Using structural equation modelling to investigate associations between environment and outcomes in technology-rich, outcomes-focused classrooms in Australian secondary schools Jeffrey P. Dorman, Jill M. Aldridge and Barry J. Fraser

\section{Chapter 18}

Designing infrastructures for learning with technology

Lasse Lipponen, Jiri Lallimo and Minna Lakkala

\section{Chapter 19}

Assessing the effectiveness of a blended web-based learning environment in an Australian High School

Vinesh Chandra and Darrell L. Fisher

\section{Chapter 20}

Validation of an instrument for assessing psychosocial environments at colleges and universities in Taiwan

Shwu-yong L. Huang 


\section{Chapter 21}

School climate in Indonesian junior secondary schools

Wahyudi and Darrell L. Fisher

\section{Chapter 22}

Turkish secondary education students' perceptions of their classroom learning environment and their attitude towards Biology

Sibel Telli, Jale Cakiroglu and Perry den Brok

\section{Chapter 23}

A brief critique on the future of learning:

Assessing the potential for research

Stephen Quinton

\section{Chapter 24}

Computer-supported collaborative learning for knowledge

Creation

Ching Sing Chai and Seng Chee Tan

\section{Chapter 25}

Evaluating the virtual learning environment

Susan M. Chard

Selected Bibliography

Index 